\title{
SEPARAÇÃO DE SERICINA UTILIZANDO ALCOÓIS E CONGELAMENTO/DESCONGELAMENTO
}

\author{
A.P.SONE ${ }^{1}$ e M. L. GIMENES ${ }^{1}$ \\ ${ }^{1}$ Universidade Estadual de Maringá - Departamento de Engenharia Química \\ E-mail para contato: anapaulasone@ @otmail.com
}

\begin{abstract}
RESUMO - A sericina é um proteína presente em torno de 20 a $30 \%$ de massa nos casulo do bicho-da-seda, Bombyx mori. É uma proteína que tem propriedades adesivas, hidrofílica, antioxidantes e antibacterianas. A sua extração pode ser feita por meio de água em ebulição e a sua separação pode ser obtida por precipitação. $\mathrm{O}$ uso dos solventes como o metanol, etanol e isopropanol e o processo decongelamento e descongelamento são investigados para a separação de sericina extraída. Nesse contexto o presente trabalho objetivou quantificar e avaliar a separação de sericina usando diferentes proporções de alcoóis e a técnica de congelamento e descongelamento e posterior secagem da sericina, de modo a obter sericina em pó. Os resultados mostram que a sericina obtida com extração com alcoóis tem características diferentes daquela obtida pela técnica de separação congelamento/descongelamento. Os melhores resultados de separação de sericina foram para o etanol a elevadas proporções.
\end{abstract}

\section{INTRODUÇÃO}

O casulo do Bombyx mori constitui-se, principalmente, de três componentes protéicos: a fibroína, a sericina e a P25. A fibroína, contem 70 a $80 \%$ da massa seca, vem a ser o principal componente do fio de seda, a sericina, compreendendo os 20-30\% restantes, é uma proteína com propriedades adesivas, fundamental na manutenção das fibras de fibroína unidas, que tem por finalidade a resistência e proteção do casulo. A P25 é uma glicoproteína com importante papel na manutenção da integridade do fio de seda. No último ainda se encontra gordura e cera, carboidratos, corantes e outros (PADAMWAR et al., 2005).

A sericina contém uma quantidade relativamente grande de aminoácidos hidrofílicos e uma estrutura amorfa. Consequentemente tem pobres propriedades mecânicas e é solúvel em soluções aquosas, sendo que a sua solubilidade aumenta com o aumento da temperatura. A solução aquosa de sericina em alta concentração é bastante viscosa, comportando-se como um adesivo (KI et.al., 2009). Sericina, que até recentemente era considerada como um produto 
residual da indústria de processamento da seda apresenta várias propriedades importantes, como a excelente absorção de umidade ( GENÇ et ai. de 2009 ), a resistência UV (PATEL E MODASIYA, 2011) anticoagulante, antioxidantes (SAROVART et al., 2003). Dado o elevado valor comercial desse produto, existe uma necessidade de desenvolver métodos de degomagem que não degradam a sericina e que também permitem a recuperação máxima do banho de desengomagem ( KI et al. de 2009 ). Recuperando a sericina de águas residuais reduz o impacto ambiental do processamento de seda e, ao mesmo tempo produz um ingrediente valioso para alimentos ( PADAMWAR et al, 2005 ), a indústria farmacêutica e cosmética.

$\mathrm{O}$ tratamento da sericina especialmente na presença de solventes orgânicos ou água afeta as mudanças estruturais da sericina de randômica para $\beta$-folhas. A sericina transformase em um estado agregado pela água e solvente orgânico. Os agregados contêm fortes ligações de hidrogênio. A forte interação intermolecular pode resultar da abundância de cadeias laterais polares, tais como grupos hidroxila e carboxila, que podem formar ligações de hidrogênio intermoleculares com outras cadeias laterais polares ou grupos amida no peptídeo. Teramoto e Miyazawa (2005) relatam que o uso de etanol para a formação de estrutura folha$\beta$ na proteínas da seda é mais efetivo que o uso do metanol. Além disso, o etanol é menos tóxico do que o metanol, o que é uma vantagem para aplicação da sericina como um biomaterial.

Deste modo, o objetivo deste trabalho équantificar e avaliar a separação de sericina usando diferentes proporções de alcoóis e a técnica de congelamento e descongelamento, de modo a obter a sericina em forma pó.

\section{MATERIAIS}

Para a obtenção da sericina, foram utilizados casulos do bicho- da-seda, Bombyx mori, cedidos pela empresa Fiação de Seda BRATAC S. A. Além da utilização de álcool metílico, álcool etílico e álcool isopropílico.

\section{PROCEDIMENTO EXPERIMENTAL}

\subsection{Extração de sericina}

Para extração da sericina, foram cortados e limpos os casulos do bicho seda em vários pedaços e colocou-se aproximadamente $18 \mathrm{~g}$ de casulos em erlenmeyer de $1000 \mathrm{~mL}$ adicionando $300 \mathrm{~mL}$ de água ultra pura, utilizando uma proporção de seis gramas de casulos secos para cada cem mililitros de água $(6: 100)(\mathrm{m} / \mathrm{v})$.

Para realização da extração em autoclave utilizou-se o equipamento da marca LS Logen Scientific, Autoclave Vertical, em pressão nanométrica de 1 kgf.cm (correspondente a $120^{\circ} \mathrm{C}$ ), por 60 minutos. Após esfriar a solução a mesma foi filtrada em peneira simples para 
separação da solução de sericina da fibroína. Após determinou-se por gravimetria e secagem a concentração (g/L) da solução de sericina.

\subsection{Precipitação da sericina}

Na separação da sericina dissolvida em água, promoveu-se a precipitação da mesma através de duas metodologias, a) utilizando solventes orgânicos: metanol, etanol, e isopropanol em diferentes proporções e b) através do método congelamento/descongelamento.

Precipitação da sericina por Solventes Orgânicos: Para o estudo do processo de precipitação utilizou-se metanol, etanol e isopropanol como solventes orgânicos nas proporções de álcool: solução de sericina (v/v): 1:1; 2:1 e; 3:1. Esta escolha de diferentes quantidades de álcool objetivou verificar qual a melhor quantidade de álcool provoca uma maior precipitação em massa da proteína sericina. A precipitação foi realizada em tubos de centrifugação de $50 \mathrm{~mL}$, previamente secos e pesados.

Inicialmente foram adicionados nos tubos de centrifugação os alcoóis na sua devida proporção e posteriormente a solução de sericina $(10 \mathrm{~mL})$, o tubo de centrifugação não foi agitado em nenhum momento da precipitação. Os tubos contendo a solução de sericina e o álcool foram armazenados em refrigerador por 24 horas com temperatura de $5^{\circ} \mathrm{C}$ para acelerar o processo de precipitação.

Para separar o precipitado do solvente, após retirar os tubos de centrifugação da geladeira utilizou-se uma centrifuga da marca Jouan GR2022, programada para 15 minutos de centrifugação, rotação de $7000 \mathrm{rpm}$ na temperatura de $20^{\circ} \mathrm{C}$. A centrifugação auxiliou-se na separação da massa de sericina e o solvente (álcool contendo água). Após centrifugação obteve-se um sobrenadante (solvente) e um precipitado (sericina). Retirou-se todo o sobrenadante do tubo com auxilio de uma pipeta e deixou-se secar toda a massa de sericina em estufa da marca Orion 515 na temperatura de $60^{\circ} \mathrm{C}$ por 48 horas. Todas as amostras foram analisadas em triplicatas.

Precipitação da sericina por congelamento/descongelamento: Este método de precipitação de sericina compreendeu o acondicionamento de uma quantidade prédeterminada $(10 \mathrm{~mL})$ de solução de sericina em congelador convencional. Esta solução ficou congelada por 24 horas.

Para determinar a massa de sericina precipitada, após retirar os tubos da geladeira, deixou os mesmos descongelarem naturalmente (temperatura ambiente de $25^{\circ} \mathrm{C}$ ) e quando a solução estava totalmente liquida centrifugou-se a mesma obtendo-se um sobrenadante (água) e um precipitado (sericina). Retirou-se todo o sobrenadante do tubo com auxilio de uma pipeta e deixou-se secar toda a massa de sericina em estufa da marca Orion 515 a $60^{\circ} \mathrm{C}$ por 72 horas. Todas as amostras foram analisadas em triplicatas 
Determinação do melhor método de precipitação da sericina: Após a evaporação de todo o solvente pesou-se os tubos de centrifugação, obtendo assim, a massa de sericina precipitada por meio de cada método de precipitação utilizando a equação 1 .

$M S=m f-m i$

Onde a $m f$ é a massa final da amostra em [g], $m_{i}$ é a massa inicial da amostra em [g]. Determinando assim qual o melhor método de precipitação.

\subsection{Obtenção da sericina em pó}

Muitas vezes é de interesse obter materiais que se encontrem no estado sólido e sem nenhum tipo de solvente, por isso verificou-se a possibilidade de obter sericina em pó através de 2 metodologias: secagem "Spray Drier" e Liofilização.

Secagem por spray drier: A secagem foi realizada utilizando-se $300 \mathrm{~mL}$ da solução de sericina obtida: a) na precipitação por congelamento/descongelamento; b) precipitação com metanol 3:1 sericina;c) precipitação etanol 3:1 sericina; e d) precipitação com isopropanol 3:1 sericina. Foram utilizadas somente as maiores proporções de alcoóis, pois foram aquelas que apresentaram maior massa de sericina precipitada. A secagem foi realizada em um mini Spray Dryer BÜCHI, B-191, com a temperatura de $171^{\circ} \mathrm{C}$, na câmara de secagem

Secagem por Liofilização: A secagem das amostras foram realizadas com o liofilizador de bancada CHRIST, Alpha 1-4 LD, equipado com bomba a vácuo PFEIFFER, D-35614, com temperatura de $-55^{\circ} \mathrm{C}$ e vácuo de 119 bar. As amostras de sericina submetidas a este processo de secagem foram obtidas após precipitação de $30 \mathrm{~mL}$ de sericina através dos metodos: a) congelamento/descongelamento; b) com metanol na proporção 3:1 sericina; c) com etanol na proporção 3:1 sericina; e d) com isopropanol na proporção 3:1 sericina. Foram utilizadas as maiores proporções de alcoóis, pois foram aquelas que apresentaram maior massa de sericina precipitada.

\section{RESULTADOS}

$\mathrm{Na}$ extração da sericina, determinou-se que $23,94 \%$ de sericina foram extraídos em relação à massa do casulo, mostrando que este resultado está dentro dos descritos em outras metodologias. A concentração da solução de sericina foi determinada antes da realização da precipitação que foi de 15,85 g. $\mathrm{L}^{-1}$. Mostrando uma grande quantidade de sericina na solução, e que essa sericina pode ser precipitada obtendo um valor significativo de massa de sólidos. 


\subsection{Precipitação da sericina}

Precipitação da sericina por Solventes Orgânicos: A sequência de utilização dos alcoóis foi conforme o aumento de cadeia carbônica, assim o metanol apresenta menor cadeia carbônica, seguido do etanol e por ultimo o isopropanol. A tabela 1 mostra que conforme aumenta a proporção de álcool, aumenta a massa de sericina precipitada.

Tabela 1: Massa de sericina obtida na precipitação com diferentes alcoóis

\begin{tabular}{cccc}
\hline $\begin{array}{c}\text { Proporção de } \\
\text { sericina: álcool }\end{array}$ & $\begin{array}{c}\text { Massa de Sericina } \\
\text { obtida na } \\
\text { precipitaçãocom } \\
\text { metanol }(\mathrm{g})\end{array}$ & $\begin{array}{c}\text { Massa de Sericina } \\
\text { obtida na } \\
\text { precipitaçãocom } \\
\text { etanol }(\mathrm{g})\end{array}$ & $\begin{array}{c}\text { Massa de Sericina } \\
\text { obtida na } \\
\text { precipitaçãocom } \\
\text { isopropanol }(\mathrm{g})\end{array}$ \\
\hline $1: 1$ & 0,128 & 0,1384 & 0,1377 \\
$1: 2$ & 0,1318 & 0,1430 & 0,1455 \\
$1: 3$ & 0,1353 & 0,1520 & 0,1498 \\
\hline
\end{tabular}

Conforme a Tabela 1, na precipitação com solventes orgânicos utilizando alcoóis (metanol, etanol e isopropanol) o que apresentou a maior massa de sericina foi o álcool etanol. Isso ocorre, pois aumentando a cadeia carbônica ocorre maior interação com a proteína. Entretanto, o álcool que apresenta a maior cadeia carbônica é o isopropanol, o qual possui maior impedimento estérico, dificultando assim a interação com a proteína. Contudo o etanol não apresenta esse impedimento e por apresentar maior cadeia carbônica que o metanol promove uma maior interação com a proteína sericina.

Em relação à proporção, conforme aumentamos a proporção de álcool maior a massa de sericina precipitada, isso se deve a maior interação intermolecular entre a proteína e o solvente. É evidente na tabela acima, que a precipitação com todos os alcoóis na proporção 3:1 sericina foi o que se obteve maior massa, seguido pela proporção álcool 2:1sericina. A proporção álcool 1:1sericina foi a que obteve-se a menor massa.

Precipitação da sericina por Congelamento/descongelamento: A precipitação da sericina utilizando o método de congelamento/descongelamento foi feita a partir de uma solução de sericina, congelada num freezer a $-10^{\circ} \mathrm{C}$ por 24 horas e descongelada naturalmente a temperatura ambiente $\left(25^{\circ} \mathrm{C}\right)$. Partindo-se de um mesmo volume de solução de sericina na mesma concentração (mesma solução mãe), obteve-se um valor médio de $0,1309 \mathrm{~g}$ de sericina seca, quando esta foi separada pelo método de congelamento/descongelamento.

Observa-se que o método de congelamento/descongelamento apresentou massa de sericina inferior a aquelas obtidas com precipitação com solventes orgânicos, em todas as proporções. Entretanto é interessante mencionar que nesse método (congelamento/descongelamento) não se utiliza solvente algum, o que torna este método mais desejável economicamente, sem o efeito do solvente orgânico na estrutura da proteína. 
Da Figura 1, obtém-se uma comparação entre todos os métodos de precipitação utilizados para precipitar sericina.

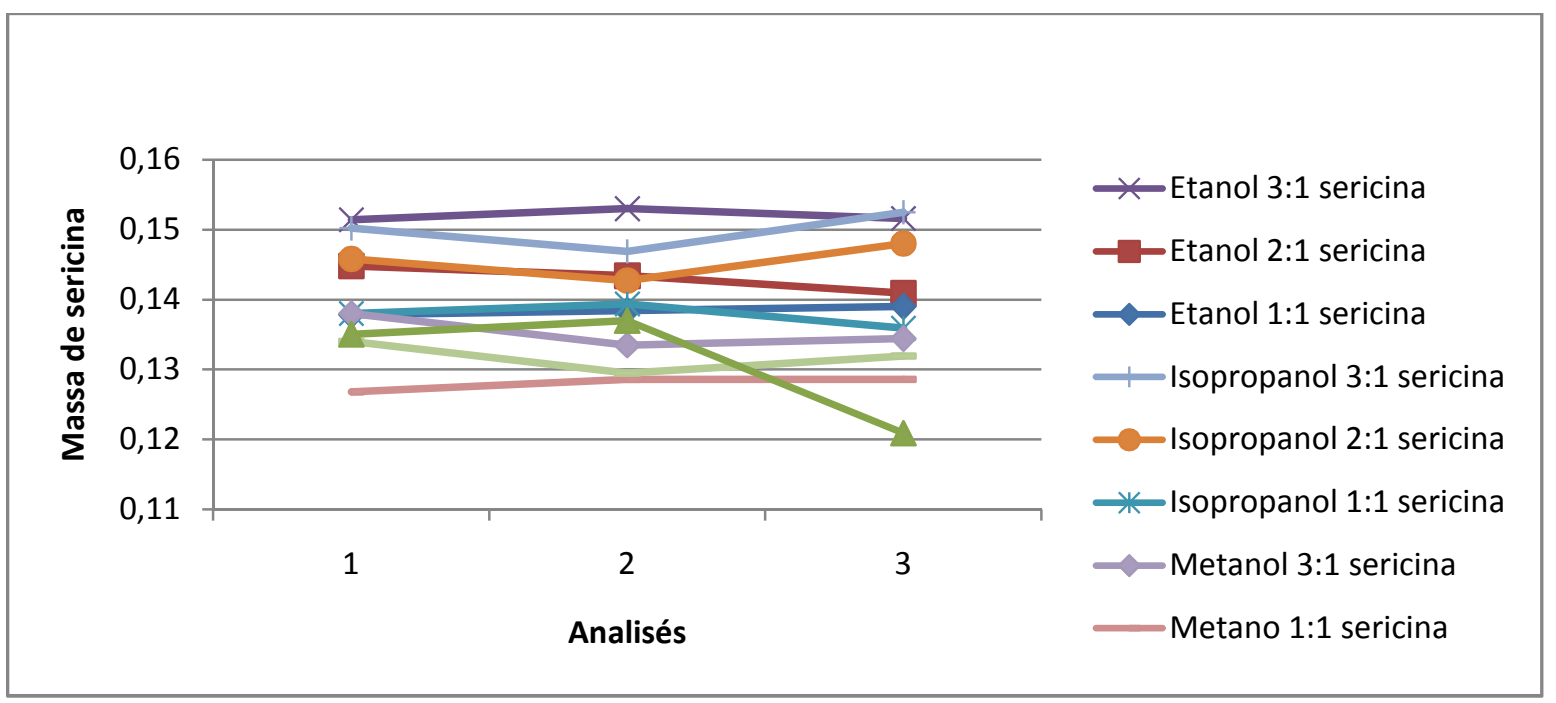

Figura 1: Variação das 3 replicas de cada amostras utilizando todos os métodos de precipitação em todas as proporções.

É interessante ressaltar a interação que o solvente pode ter com a proteína. Segundo Teramoto e Miyazawa (2005) o uso de alcoóis altera a estrutura da sericina. Essa mudança de estrutura não será observada quando se utiliza o método de congelamento/descongelamento. Assim conclui-se que a precipitação com solventes orgânicos, obtêm-se maior quantidade de massa seca, contudo estruturas alteradas. Quando se utiliza somente água estas estruturas não serão alteradas mais a massa seca obtida é menor em quantidade.

\subsection{Obtenção de sericina em pó}

Para obtenção de sericina em pó, foram utilizados amostras de sericina precipitada com os solventes orgânicos (metanol, etanol, isopropanol) nas proporções 3:1 (álcool/sericina), e também amostras de solução de sericina obtida com o método de precipitação por congelamento/descongelamento.

\section{$\underline{\text { Secagem por spray drier: }}$}

Amostras de sericina em pó obtida pelo método de secagem em spray drier através do a) processo de precipitação por congelamento/descongelamento; b) processo de precipitação com metanol na proporção metanol 3:1 sericina; c) processo de precipitação com etanol na proporção 3:1 sericina; e d) processo de precipitação com isopropanol na proporção 3:1 sericina, estão apresentadas na Figura 2, 


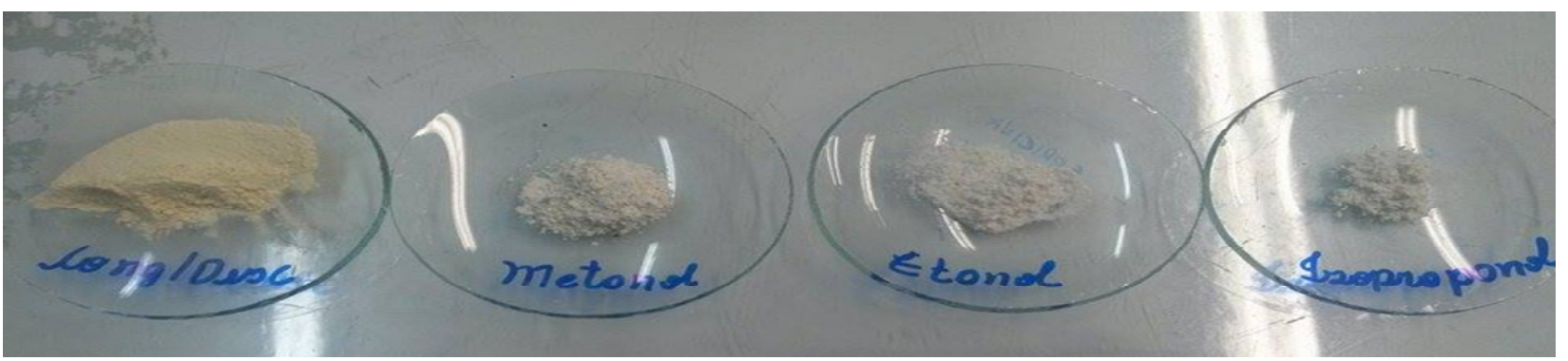

Figura 3: Sericina em pó obtida pela secagem em spray drier.

Observa-se visualmente que a sericina em pó obtida pelo método de precipitação em alcoóis apresenta coloração mais clara, diferente da obtida pelo método de congelamento/descongelamento. Isso devido as mudanças estruturais que o álcool causa na proteína.

Secagem por Liofilização: As amostras de sericina em pó obtidas por este método de secagem pode ser observadas na Figura 3.

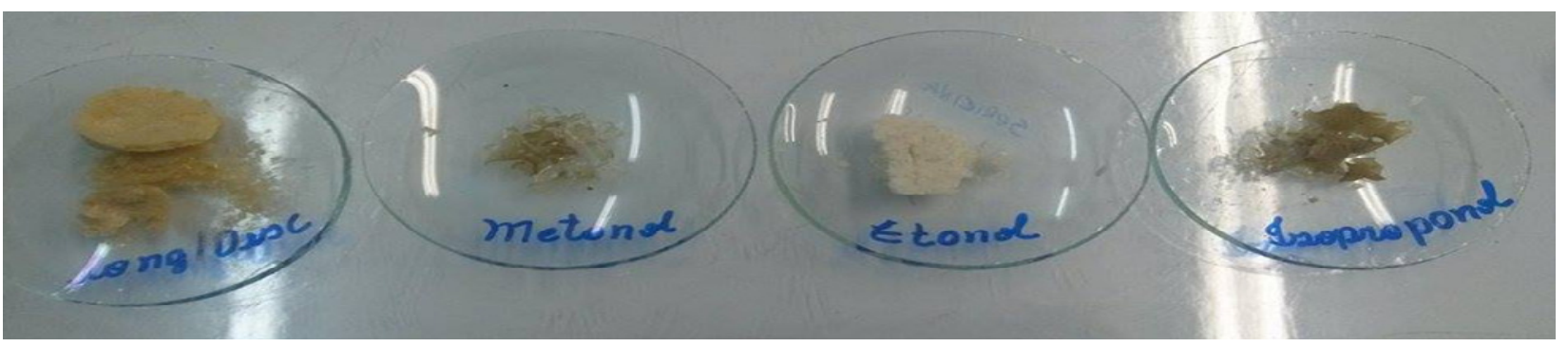

Figura 3: Sericina em pó obtida pela secagem em liofilizador.

As amostras obtidas por liofilização não apresentam todas a mesma coloração, demonstrando um material de aparência irregular, principalmente para as amostras em que foram usadas metanol e isopropanol na precipitação. De uma maneira geral, o aspecto visual das sericinas em pó obtidas na secagem spray drier é muito melhor que aquelas obtidas por liofilização.

O método de precipitação com solvente altera a estrutura da sericina, pois a coloração da sericina é visualmente diferente. Posteriormente, em trabalho futuro, serão investigadas asas mudanças estruturais causada por cada método de precipitação e também pela secagem.

\section{CONCLUSÃO}

Dentre os métodos de separação da sericina por precipitação com álcoois, verificou-se que o solvente orgânico etanol é o mais eficiente entres os alcoóis analisados (metanol, etanol e isopropanol), e que a proporção 3:1 de etanol/sericina foi qual obteve uma maior massa seca de sericina. Alternativamente, pode-se obter sericina separada por processo físico sem uso de solvente - processo de congelamento/descongelamento. Esse processo em 
comparação com os processos que utiliza álcool como solvente, apresenta um menor rendimento de sericina, mas a vantagem da inexistência do solvente que tem ação em modificar a estrutura da proteína.

O método de secagem para obter sericina em pó influencia as características domaterial, afetando o aspecto visual e a coloração. A secagem spray é a que apresenta melhor características para obter sericina em pó.

\section{REFERENCIAS}

GENÇ, G., BAYRAKTAR, O., BASAL, G., 2009. A research on the production of silk sericina powders by using spray drying method. Tekstilve Konfeksiyon 19 (4), 273e 279.

KI, C. S.; PARK, Y. H. Silk Protein as a Fascinating Biomedical Polymer: StructuralFundamentals and Applications. Macromolecular Research, v. 17, $\mathrm{N}^{\circ} .12$, p. $935-$ 942, 2009.

PADAMWAR, M. N.; PAWAR, A. P.; DAITHANKAR, A.V.; MAHADIK, K.R. SilkSericin as a moisturizer: an in vivo study. Journal of Cosmetic Dermatology, v.4, p. 250-257, 2005.

PATEL, R.J., MODASIYA, M.K., 2011. Sericin-pharmaceutical applications.Int. J. Res. Pharm. Biomed.Sci. 2, 913e917.

SAROVART, S., SUDATIS, B., MEESILPA, P., GRADY, B.P., MAGARAPHAN, R., 20 03.The use of sericin as anantioxidant and antimicrobial for polluted air treatment. Rev. Adv. Mater. Sci. 5, 193e198.

TERAMOTO, J., MIYAZAWA, M. Molecular orientation behaviour of silk sericin film as revealed by ATR infrared spectroscopy. Biomacromolecules, v. 6, p. 2049-2057, 2005

ZHANG, Y. Q. Application of natural silk protein sericin in biomaterials. Biotechnology Advances, v. 20, p. 91-100, 2002. 